\title{
Diagnostic approach for myocardial contusion: a retrospective evaluation of patient data and review of the literature
}

\author{
Esther M. M. Van Lieshout ${ }^{1} \cdot$ Michael H. J. Verhofstad ${ }^{1} \cdot$ Dirk Jan T. Van Silfhout ${ }^{1}$. Eric A. Dubois ${ }^{2}$
}

Received: 17 October 2019 / Accepted: 14 January 2020 / Published online: 25 January 2020

(c) The Author(s) 2020

\begin{abstract}
Purpose Myocardial contusion can be a life-threatening condition in patients who sustained blunt thoracic trauma. The diagnostic approach remains a subject of debate. The aim of this study was to determine the sensitivity and specificity of echocardiography, electrocardiography, troponins T and I (TnT and TnI), and creatine kinase muscle/brain (CK-MB) for identifying patients with a myocardial contusion following blunt thoracic trauma.

Methods Sensitivity and specificity were first determined in a 10-year retrospective cohort study and second by a systematic literature review with meta-analysis.

Results Of the 117 patients in the retrospective study, 44 (38\%) were considered positive for myocardial contusion. Chest X-ray, chest CT scan, electrocardiograph, and echocardiography had poor sensitivity $(<15 \%)$ but good specificity $(\geq 90 \%)$. Sensitivity to cardiac biomarkers measured at presentation ranged from 59\% for TnT to $77 \%$ for hs-TnT, specificity ranged from $63 \%$ for CK-MB to $100 \%$ for TnT. The systematic literature review yielded 28 studies, with $14.5 \%$ out of 7242 patients reported as positive for myocardial contusion. The pooled sensitivity of electrocardiography, troponin I, and CK-MB was between 62 and $71 \%$, versus only $45 \%$ for echocardiography and $38 \%$ for troponin T. The pooled specificity ranged from $63 \%$ for CK-MB to $85 \%$ for troponin $\mathrm{T}$ and $88 \%$ for echocardiography.

Conclusion The best diagnostic approach for myocardial contusion is a combination of electrocardiography and measurement of cardiac biomarkers. If abnormalities are found, telemonitoring is necessary for the early detection of life-threatening arrhythmias. Chest X-ray and CT scan may show other thoracic injuries but provide no information on myocardial contusion.
\end{abstract}

Keywords Echocardiography $\cdot$ Electrocardiography $\cdot$ Myocardial contusion $\cdot$ Specificity $\cdot$ Troponin

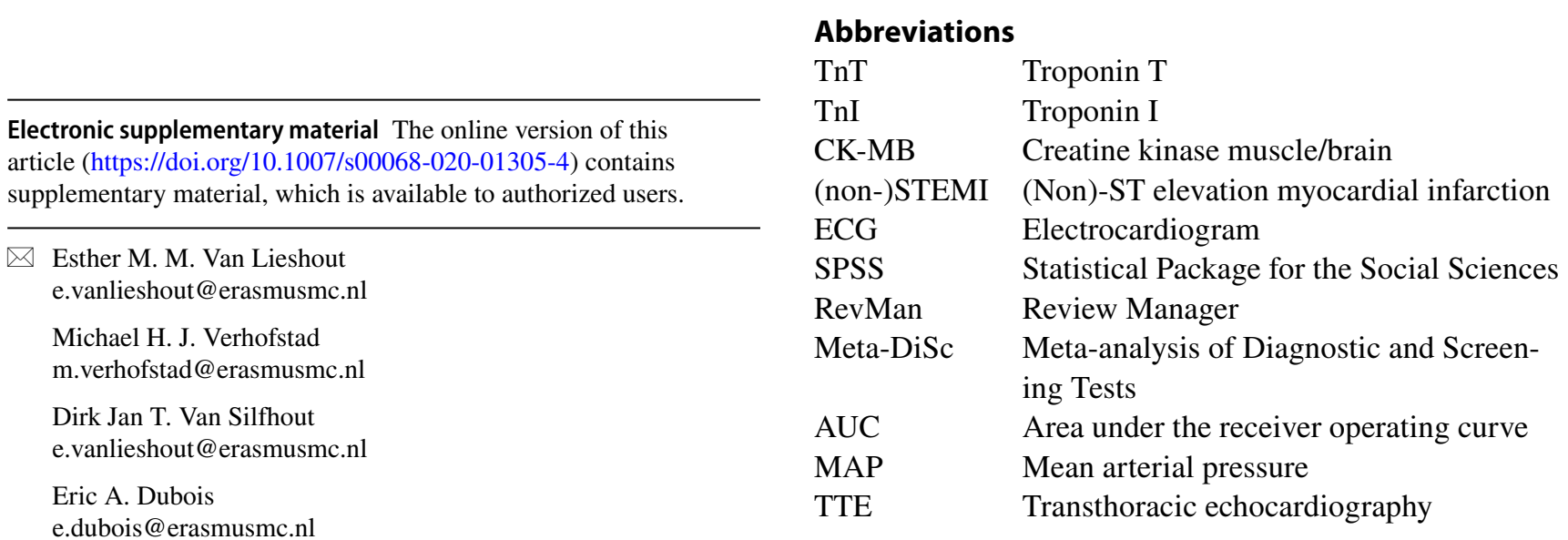

1 Trauma Research Unit Department of Surgery, Erasmus MC, University Medical Center Rotterdam, P.O. Box 2040, 3000 CA Rotterdam, The Netherlands

2 Department of Cardiology, Erasmus MC, University Medical Center Rotterdam, P.O. Box 2040, 3000 CA Rotterdam, The Netherlands 


\section{Background}

Myocardial contusion describes a condition of bruising or (microscopically small) hemorrhaging of the heart muscle caused by blunt thoracic trauma. In patients who have sustained blunt thoracic trauma, the prevalence of myocardial contusion ranges from 0 to $76 \%$, depending on the diagnostic criteria used [1-10].

The bruising is generally caused by a decelerating force on the anterior side of the thorax [11-14]. First, the heart is abruptly pressed to the dorsal side of the sternum causing a bruise on the anterior side ('coup'). Depending on the amount of energy that needs and can be absorbed by the rib cage, the thoracic spine can hit the heart at the posterior side, resulting in a second bruise ('contrecoup'). In a final stage, the distance between the sternum and spine will reduce further, resulting in septal or intracardiac structural injuries.

The absence of a clear definition and the fact that there is no accepted gold standard in complementary tests makes diagnosing myocardial contusion difficult. The diagnostic approach of myocardial contusion as well as its clinical course remain subject to debate, because of heterogeneity in clinical presentation and the unpredictable natural course [1,15-20]. The decelerating force can not only lead to mechanical cardiac injuries, such as rupture of atria or chordae, the bruising may also lead to other cardiac adverse events, varying from mild arrhythmias like premature ventricular complexes, to atrial fibrillation or ventricular fibrillation $[2-5,11-16]$. The vast majority of patients who develop arrhythmia after a myocardial contusion do so within $24 \mathrm{~h}$ after trauma [13,21-25]. Whereas on admission to the emergency department a large proportion of patients who sustained blunt thoracic trauma do not show cardiac symptoms indicative of myocardial contusions, clinicians should be prepared for rapid changes in clinical condition of such patients as severe arrhythmia or even cardiac arrest can occur within $72 \mathrm{~h}[26,27]$.

Myocardial contusion is often accompanied by significant extracardiac injuries which may have hemodynamic effects, thereby hampering the possible diagnosis of a myocardial contusion. Patients with hemodynamic changes but without a clear bleeding or cardiac tamponade are very suspect for myocardial contusion [8, 14, 24]. On the other hand, pulmonary contusion, a sternum fracture, or multiple rib fractures should warn the treating physician to be aware of a possible myocardial contusion. Therefore, the relevance of complete diagnostics should not be underestimated after typical trauma mechanisms, even when the first impression on patient's clinical condition does not indicate severe injury.

Although several diagnostic tests are available, none of them have shown sufficient diagnostic accuracy for diagnosing myocardial contusion [19, 22, 28-32]. Especially for patients who sustained a high-energy trauma but have no clear symptoms or signs (yet), selecting those who require careful observation or telemonitoring from those who can go home safely, is paramount. Echocardiography and electrocardiography may indicate damage to the tissue architecture and subsequent complications, but information on specific cellular damage within the heart muscle requires measurement of cardiac muscle-specific proteins such as troponin $\mathrm{T}(\mathrm{TnT})$, troponin $\mathrm{I}(\mathrm{TnI})$, or creatine kinase muscle and brain isoenzyme (CK-MB) [2, 28, 29, 33-39]. Since tissue damage cannot occur without cellular damage, whereas the opposite can, a combination of tests is commonly performed.

However, no consensus exists in the optimal diagnostic workup for patients with a possible myocardial contusion. To develop a diagnostic protocol, more insight into the diagnostic properties of the tests available is needed. Therefore, the aim of this study was to determine sensitivity and specificity of echocardiography, electrocardiography, troponins $\mathrm{T}$ and I, and CK-MB to identify patients with a myocardial contusion following blunt thoracic trauma. This was done both in a retrospective cohort and by systematic literature review with a meta-analysis.

\section{Methods}

\section{Retrospective cohort study}

Patients presented to a level I trauma center with a suspected myocardial contusion after blunt force thoracic trauma between January 1, 2007, and June 30, 2017, were considered eligible for this single-center retrospective cohort study. The study was exempted by the local Medical Research Ethics Committee.

Potentially eligible patients (i.e., patients for whom myocardial contusion could have been considered) were identified using two strategies. Searching electronic hospital discharge letters and correspondence to General Practitioners that mentioned myocardial contusion (or any synonym possible) resulted in a list of admitted and nonadmitted patients. Patients who were admitted to the hospital were also identified from the National Trauma Registry by searching for patients with a registered Abbreviated Injury Score (AIS) for any myocardial injury. The AIS1998 codes were 441099.1, 441002.1, 441004.1, 441006.4, 441008.3, 441010.3, 441012.5, 441014.6, 441016.6, 441018.6, 441200.5, and 441300.5. The AIS-2005 codes were 441089.9, 441099.1, 441002.1, 441004.1, 441006.4, 114008.3, 441010.3, 441012.5, 441013.5, 441014.6, 441016.6, 441018.6, 441200.5, 441300.5, and 440400.5. Two authors (DJTVS and EAD) identified the eligible 
patients from these lists. All patients in whom a myocardial contusion was considered were included. Consideration of a myocardial contusion had to be clear from the physician's notes in the patient's medical files and could due to results of anamnesis or diagnostic tests. Exclusion criteria were (1) no suspicion of myocardial contusion; (2) trauma mechanism other than blunt trauma; (3) confirmed (non)-ST elevation myocardial infarction [(non-)STEMI]; (4) no diagnostic or outcome data available.

Patient characteristics, injury characteristics, results from patient history, physical examination, diagnostic tests (chest CT-scan, chest X-ray, electrocardiography, echocardiography, and levels of cardiac biomarkers) were collected from medical records. During hospital stay, relevant findings during clinical and telemetric observation, electrocardiography, transthoracic echocardiography, levels of cardiac biomarkers, cardiac adverse events, mortality, and surgical interventions were also collected from the patient's medical files. Patient characteristics included gender, age at trauma, comorbidities, use of medication that either mask or cause cardiac arrhythmia, and renal function (i.e., eGFR at admission). Thoracic injury characteristics are rib fractures, hemothorax, pneumothorax, cardiac valve defects, sternum fracture, flail chest, pulmonary contusion, and aorta dissection. Details on patient history and physical examination were complaints of chest pain, palpitations, dyspnea, fainting, cardiac murmurs, cardiac rubbing, oxygen saturation, heart rate, systolic and diastolic blood pressure, and Glasgow Coma Score.

Diagnostic tests were checked for signs of abnormalities. For chest CT and X-ray, suspicion of the presence of pericardial effusion was collected from the radiology report. Electrocardiograms (ECGs) were reviewed by a cardiologist (EAD) for signs of ST elevation, ST depression, T-wave inversion, arrhythmia, or intraventricular conduction abnormalities. Transthoracic echocardiography was reviewed (by EAD) for signs of regional wall motion abnormalities, pericardial effusion, or mechanical abnormalities. No transesophageal echocardiography was performed.

Thresholds for increased levels of cardiac biomarkers were $30 \mathrm{ng} / \mathrm{L}$ for normal-sensitive troponin $\mathrm{T}$ (used until December 31, 2012) and $14 \mathrm{ng} / \mathrm{L}$ for high-sensitive troponin $\mathrm{T}$ (used since January 1, 2013). Cut-off values for creatine kinase MB (CK-MB) were $7.6 \mu \mathrm{g} / \mathrm{L}$ for men and $4.7 \mu \mathrm{g} / \mathrm{L}$ for women.

Relevant findings during clinical observation with or without telemetry, levels of cardiac biomarkers, electrocardiography, echocardiography, and cardiac adverse events that might suggest myocardial contusion were registered. Relevant cardiac adverse events were arrhythmias (i.e., atrial fibrillation or flutter, premature ventricular complexes, and supraventricular tachycardia), hypotension, and cardiogenic shock requiring inotropic support. In addition, data on relevant surgical interventions, its outcome, and mortality were collected.

Based upon all available data and final judgement of the treating physician as mentioned in the patient's medical files, patients were categorized as having had a myocardial contusion or not. Diagnostic tests were also categorized as positive or negative for myocardial contusion. No single test could serve as a gold standard for the diagnosis. Signs indicative of myocardial contusion are (1) elevated cardiac biomarkers; (2) new valve defects, regional wall motion abnormalities, pericardial effusion, or other anatomical defects seen on echocardiography; (3) intraventricular conduction abnormalities, atrial fibrillation, premature ventricular complexes, and supraventricular tachycardia seen on electrocardiography.

Data were analyzed using the Statistical Package for the Social Sciences version 24.0 (SPSS, Chicago, IL, USA) and MedCalc (https://www.medcalc.org/calc/diagnostic_test. php). Patients with versus patients without myocardial contusion were compared. Normality of continuous data was tested with the Shapiro-Wilk test, which showed that all were non-normally distributed. Continuous data are shown as median with quartiles and categorical data are shown as numbers with percentage. Statistical significance between the two groups was assessed using a Mann-Whitney $U$ test for continuous data and a Chi-square test or Fisher exact test for categorical data. A two-sided $p$ value $<0.05$ was used as threshold of statistical significance. For each diagnostic test, myocardial contusion prevalence, sensitivity, and specificity were calculated and are reported as percentage with 95\% confidence.

\section{Literature review}

A literature search was performed on November 11, 2018, using Embase.com, Medline Ovid, Web of Science, Cochrane CENTRAL and Google Scholar databases. Databases were searched since their inception. The full search string is shown in Supplemental Figure S1. Studies were eligible for inclusion if they discussed tests applied to patients with a suspected myocardial contusion after blunt thoracic trauma. If no 'myocardial contusion' and 'non-myocardial contusion' group were mentioned, or if the diagnostic test that differentiated between the two groups was not known, the study was excluded. Studies on pediatric patients, animal studies, non-English studies, systematic reviews, metaanalyses, descriptive studies, and case reports were also excluded.

Literature selection and data extraction were done by two authors (DJTVS and EAD) independently. Any disagreement was resolved by consensus. First, titles and abstracts of all manuscript were reviewed for eligibility. Next, the full text of all remaining studies was screened for eligibility. For 
all included studies, the reference list was reviewed for identifying studies that were missed during the selection process.

Risk of bias assessment and applicability concerns for each study was carried out using the QUADAS-2 tool. For each study, the following data were extracted: author, publication year, study design, study population size, mean age, number of patients diagnosed with myocardial contusion, and the number of patients with ischemic heart disease or acute myocardial infarction. For echocardiography, electrocardiography, and cardiac biomarkers, the number of true and false positives and negatives were extracted for each study. In addition, the reference test and cut-off values for cardiac biomarkers used for identifying the myocardial contusion group were recorded.

Sensitivity and specificity were calculated using Review Manager (RevMan version 5.3, Copenhagen; The Nordic Cochrane Center, The Cochrane Collaboration, 2014). Subsequent meta-analysis was done using Meta-analysis of Diagnostic and Screening Tests (Meta-DiSc) [40]. Sensitivity and specificity were pooled across all studies, and a summary receiver operating curve was made. For each different diagnostic test, sensitivity and specificity are reported as percentage with $95 \%$ confidence interval. The area under the receiver operating curve (AUC) is reported with its standard error.

\section{Results}

\section{Retrospective cohort study}

A total of 611 patients were identified by searching the hospital database $(n=372)$ and the trauma registry $(n=239$; Fig. 1). After studying the electronic medical records, 494 patients were excluded: 378 patients had not been suspected for myocardial contusion, 57 had not sustained blunt thoracic trauma, 21 had a confirmed myocardial infarction, and for 38 patients, diagnostic or outcome data were not

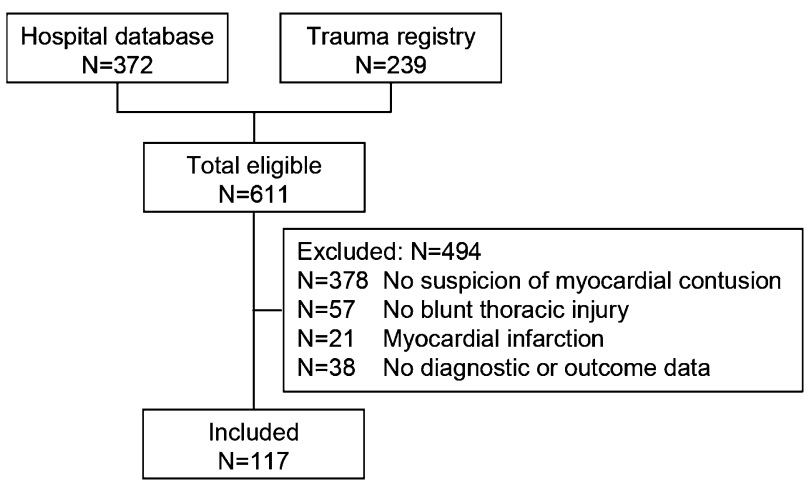

Fig. 1 Flowchart of retrospective cohort study available. The remaining 117 patients were admitted with a suspicion of myocardial contusion. Forty-four were diagnosed with a myocardial contusion and 73 were not. The study population had a median age of $43\left(\mathrm{P}_{25}-\mathrm{P}_{75} 31-62\right)$ years (Table 1), $83(71 \%)$ patients were male and $16(14 \%)$ had a known unrelated (cardiopulmonary) disorder. These patient characteristics at presentation did not differ between patients with myocardial contusion and those without myocardial contusion, nor did kidney function. Three patients used either citalopram, paroxetine, or methadone.

The rate of non-cardiac thoracic injuries was higher in patients with a myocardial contusion $(n=40 ; 91 \%)$ than in those who were not diagnosed with a myocardial contusion ( $n=54 ; 74 \% ; p=0.031)$. The four most common injuries were a sternum fracture, rib fracture(s), pneumothorax, and pulmonary contusion. Rib fractures occurred more often in patients with a myocardial contusion than patients without (68\% versus $42 \%$; $p=0.008$ ). The same was true for pulmonary contusion $(43 \%$ versus $23 \%$; $p=0.038)$. Rates of all other thoracic injuries were similar in both groups.

Details of patient history could be found for $80 \%$ of patients; $39(41 \%)$ patients had chest pain, $4(4 \%)$ had dyspnea, 1 (1\%) had palpitations, and none had cardiac rubbing (Table 2). None of these differed between the two groups. Results of physical examination were available for all 117 patients. Patients with a myocardial contusion had a higher median heart rate $\left(97 \mathrm{bpm} ; \mathrm{P}_{25}-\mathrm{P}_{75} 82-114\right.$ versus $\left.80 ; \mathrm{P}_{25}-\mathrm{P}_{75} 72-92 ; p<0.001\right)$, a lower median mean arterial pressure (MAP) (94 mmHg; $P_{25}-P_{75} 73-107$ versus $\left.100 \mathrm{mmHg} ; P_{25}-P_{75} 94-110 ; p=0.037\right)$, and a lower median Glasgow Coma Scale $\left(15 ; P_{25}-P_{75} 5-15\right.$ versus $15 ; P_{25}-P_{75}$ 15-15; $p=0.001)$.

Chest CT scan, electrocardiography, and transthoracic echocardiography made at hospital presentation were indicative of myocardial contusion in only one patient who showed retrosternal hematoma (Table 2). Five patients without myocardial contusion also showed retrosternal hematoma on the CT scan. Chest X-ray was unremarkable in all patients. On the other hand, levels of cardiac biomarkers TnT, hs-TnT, and $\mathrm{CK}-\mathrm{MB}$ were consistently higher in patients with a myocardial contusion than in patients without.

Overall, 111 patients with a suspected myocardial contusion were admitted for observation. Telemonitoring was done in $91 \%$ of patients with a myocardial contusion versus $59 \%$ of patients without myocardial contusion $(p<0.001)$. Abnormalities suggestive of myocardial contusion at the electrocardiography made during admission were shown only in one patient with a myocardial contusion. Levels of cardiac biomarkers remained higher at follow-up in patients with a myocardial contusion than in patients without, as was the case in the initial screening.

The diagnostic properties for myocardial contusion of all diagnostic tests evaluated performed at presentation and 
Table 1 Patient and injury characteristics of patients with versus without myocardial contusion

\begin{tabular}{|c|c|c|c|c|}
\hline Parameter & Overall $(n=117)$ & $\begin{array}{l}\text { Myocardial con- } \\
\text { tusion }(n=44)\end{array}$ & $\begin{array}{l}\text { No myocardial } \\
\text { contusion }(n=73)\end{array}$ & $p$ value \\
\hline \multicolumn{5}{|l|}{ Patient characteristics } \\
\hline Male gender & $83(71 \%)$ & $34(77 \%)$ & $49(67 \%)$ & 0.296 \\
\hline Age & $43(31-62)$ & $39(23-64)$ & $46(34-61)$ & 0.518 \\
\hline Comorbidity & $16(14 \%)$ & $5(11 \%)$ & $11(15 \%)$ & 0.782 \\
\hline Cardiac & $14(12 \%)$ & $4(9 \%)$ & $10(14 \%)$ & ND \\
\hline Pulmonary & $3(3 \%)$ & $2(5 \%)$ & $1(1 \%)$ & ND \\
\hline Kidney transplant & $1(1 \%)$ & $1(2 \%)$ & $0(0 \%)$ & ND \\
\hline Medication $^{\mathrm{a}}$ & $3(3 \%)$ & $0(0 \%)$ & $1(4 \%)$ & 0.290 \\
\hline Citalopram & $1(1 \%)$ & $0(0 \%)$ & $1(1 \%)$ & ND \\
\hline Paroxetine & $1(1 \%)$ & $0(0 \%)$ & $1(1 \%)$ & ND \\
\hline Methadone & $1(1 \%)$ & $0(0 \%)$ & $1(1 \%)$ & ND \\
\hline eGFR at admission (mL/minute) & $90(75-105)$ & $89(68-107)$ & $90(79-104)$ & 0.566 \\
\hline \multicolumn{5}{|l|}{ Thoracic injuries } \\
\hline Thoracic injury & $94(80 \%)$ & $40(91 \%)$ & $54(74 \%)$ & 0.031 \\
\hline Sternum fracture & $67(57 \%)$ & $23(52 \%)$ & $44(60 \%)$ & 0.443 \\
\hline Rib fracture & $61(52 \%)$ & $30(68 \%)$ & $31(42 \%)$ & 0.008 \\
\hline Pneumothorax & $40(34 \%)$ & $19(43 \%)$ & $21(29 \%)$ & 0.159 \\
\hline Pulmonary contusion & $36(31 \%)$ & $19(43 \%)$ & $17(23 \%)$ & 0.038 \\
\hline Hemothorax & $18(15 \%)$ & $10(23 \%)$ & $8(11 \%)$ & 0.114 \\
\hline Flail chest & $6(5 \%)$ & $2(5 \%)$ & $4(5 \%)$ & 1.000 \\
\hline Aorta rupture & $2(2 \%)$ & $2(5 \%)$ & $0(0 \%)$ & ND \\
\hline Valve abnormalities & $1(1 \%)$ & $1(2 \%)$ & $0(0 \%)$ & ND \\
\hline
\end{tabular}

Data are shown as $n(\%)$ or median $\left(\mathrm{P}_{25}-\mathrm{P}_{75}\right)$

$e G F R$ estimated glomerular filtration rate, $N D$ not determined

${ }^{a}$ None of the patients had used amiodarone, haloperidol, flecainide, sotalol, macrolide antibiotics, cotrimoxazole, amitriptyline, bupropion, fluoxetine, sertraline, venlafaxine, domperidone, or ondansetron during follow-up are shown in Table 3. Chest X-ray, chest CT scan, electrocardiography, and echocardiography all had a poor sensitivity $(<15 \%)$ but a good specificity $(\geq 90 \%)$. Diagnostic performance is much better for the cardiac biomarkers. Sensitivity ranged from $59 \%$ for TnT to $77 \%$ for hsTnT, measured at presentation. Repeated cardiac biomarkers even had a sensitivity of $86 \%$ for TnT and $93 \%$ for hs-TnT. Specificity for measurements at presentation and follow-up was excellent for TnT (100\% and 93\%) and good for hs-TnT ( $85 \%$ and $81 \%$ ), but moderate to poor for CK-MB (63\% and $44 \%)$. Plot of the cardiac biomarkers over time for patients with myocardial contusion that did not have elevated marker expression at presentation is shown in Fig. 2. This shows that six out of nine patients with normal TnT values at presentation had elevated TnT expression at both repeated measurements (Fig. 2a). Likewise, four out of five patients with normal hs-TnT expression at presentation had elevated levels at follow-up (Fig. 2b). For CK-MB, four out of seven males and both females had elevated CK-MB expression, following normal expression at presentation (Fig. 2c, d).

Thirty-three cardiac adverse events had developed in 18 patients (Table 4). Patients with myocardial contusion had a larger rate of cardiac adverse events $(n=15 ; 34 \%)$ than controls $(n=3 ; 4 \% ; p<0.001)$. The most common adverse event was arrhythmia, which was seen in 13 patients with a myocardial contusion (versus two in patients without myocardial contusion). Eight of these 13 patients with a myocardial contusion had atrial fibrillation or flutter. Rib fractures occurred more often in patients who developed an adverse event: 12 out of 18 (67\%) patients with an adverse event had fractured ribs, versus 49 out of 99 (49\%) in patients who remained free of adverse events. Seven patients died, four patients with a myocardial contusion and three patients without myocardial contusion. Of the patients with myocardial contusion, one patient died of cardiogenic shock due to a known mitral valve dysfunction; in two other patients, treatment was stopped due to infaust neurological prognosis after trauma. In the fourth patient, no cause of death was noted and autopsy was not performed. One patient without myocardial contusion died of pulmonary embolism, the other two due to infaust neurological prognosis after trauma. 
Table 2 Results from patient history and physical examination of patients with versus without myocardial contusion

\begin{tabular}{|c|c|c|c|c|}
\hline Parameter & Overall $(n=117)$ & $\begin{array}{l}\text { Myocardial con- } \\
\text { tusion }(n=44)\end{array}$ & $\begin{array}{l}\text { No myocardial } \\
\text { contusion }(n=73)\end{array}$ & $p$ value \\
\hline \multicolumn{5}{|l|}{ Diagnostic item at presentation } \\
\hline Patient history recorded & $94(80 \%)$ & $30(68 \%)$ & $64(88 \%)$ & 0.016 \\
\hline Chest pain & $39 / 94(41 \%)$ & $9 / 30(30 \%)$ & $30 / 64(47 \%)$ & 0.178 \\
\hline Dyspnea & $4 / 94(4 \%)$ & $3 / 30(10 \%)$ & $1 / 64(2 \%)$ & 0.094 \\
\hline Palpitations & $1 / 94(1 \%)$ & $1 / 30(3 \%)$ & $0 / 64(0 \%)$ & ND \\
\hline Physical examination recorded & $117(100 \%)$ & $44(100 \%)$ & $73(100 \%)$ & ND \\
\hline Cardiac murmurs & $3 / 117(3 \%)$ & $2 / 44(5 \%)$ & $1 / 73(1 \%)$ & 0.555 \\
\hline Heart rate (bpm) & $85(74-100)$ & $97(82-114)$ & $80(72-92)$ & $<0.001$ \\
\hline MAP (mmHg) & $80(70-89)$ & $94(73-107)$ & $100(94-110)$ & 0.024 \\
\hline Chest X-ray abnormality & $0 / 114(0 \%)$ & $0 / 42(0 \%)$ & $0 / 72(0 \%)$ & ND \\
\hline Chest CT scan abnormality & $6 / 83(7 \%)$ & $1 / 33(3 \%)$ & $5 / 50(10 \%)$ & 0.395 \\
\hline ECG abnormality & $10 / 96(10 \%)$ & $5 / 35(14 \%)$ & $5 / 61(8 \%)$ & 0.489 \\
\hline TTE abnormality & $1 / 35(3 \%)$ & $1 / 10(10 \%)$ & $0 / 25(0 \%)$ & 0.286 \\
\hline TnT measured & $51(44 \%)$ & $22(50 \%)$ & $29(40 \%)$ & 0.337 \\
\hline $\operatorname{TnT}(\mathrm{ng} / \mathrm{L})$ & $0(0-40)$ & $55(0-283)$ & $0(0-0)$ & $<0.001$ \\
\hline TnT elevated & $13 / 51(25 \%)$ & $13 / 22(59 \%)$ & $0 / 29(0 \%)$ & $<0.001$ \\
\hline Hs-TnT measured & $61(52 \%)$ & $22(50 \%)$ & $39(53 \%)$ & 0.849 \\
\hline Hs-Tnt (ng/L) & $10(5-25)$ & $28(19-57)$ & $5(3-11)$ & $<0.001$ \\
\hline Hs-TnT elevated & $23 / 61(38 \%)$ & $17 / 22(77 \%)$ & $6 / 39(15 \%)$ & $<0.001$ \\
\hline CK-MB measured & $108(92 \%)$ & $44(100 \%)$ & $64(88 \%)$ & 0.013 \\
\hline CK-MB $(\mu \mathrm{g} / \mathrm{L})$ & $8(4-17)$ & $15(7-28)$ & $5(3-10)$ & $<0.001$ \\
\hline CK-MB elevated & $57 / 108(53 \%)$ & $33 / 44(75 \%)$ & $24 / 75(38 \%)$ & $<0.001$ \\
\hline \multicolumn{5}{|l|}{ Diagnostic item at follow-up } \\
\hline Observation & $111(95 \%)$ & $43(98 \%)$ & $68(93 \%)$ & 0.407 \\
\hline Telemonitoring & $83(71 \%)$ & $40(91 \%)$ & $43(59 \%)$ & $<0.001$ \\
\hline Telemonitoring (days) & $2(2-7)$ & $4(2-10)$ & $2(2-3)$ & 0.057 \\
\hline ECG abnormality & $3 / 37(8 \%)$ & $1 / 17(6 \%)$ & $2 / 20(10 \%)$ & 1.000 \\
\hline Time to repeated lab tests (h) & $4(3-6)$ & $4(3-7)$ & $4(3-6)$ & 0.833 \\
\hline TnT measured & $48(41 \%)$ & $21(48 \%)$ & $27(37 \%)$ & 0.332 \\
\hline TnT (ng/L) & $0(0-148)$ & $180(55-1295)$ & $0(0-0)$ & $<0.001$ \\
\hline TnT elevated & $20(42 \%)$ & $18(86 \%)$ & $2(7 \%)$ & $<0.001$ \\
\hline Hs-TnT measured & $52(44 \%)$ & $21(48 \%)$ & $31(42 \%)$ & 0.701 \\
\hline Hs-Tnt (ng/L) & $12(6-56)$ & $56(31-127)$ & $8(5-12)$ & $<0.001$ \\
\hline Hs-TnT elevated & $25(48 \%)$ & $19(90 \%)$ & $6(19 \%)$ & $<0.001$ \\
\hline CK-MB measured & $95(81 \%)$ & $40(91 \%)$ & $55(75 \%)$ & 0.050 \\
\hline CK-MB ( $\mu \mathrm{g} / \mathrm{L})$ & $14(6-29)$ & $23(11-43)$ & $9(4-18)$ & $<0.001$ \\
\hline CK-MB elevated & $68(72 \%)$ & $37(93 \%)$ & $31(56 \%)$ & $<0.001$ \\
\hline
\end{tabular}

Data are shown for the diagnostic modalities at presentation to hospital

Troponin I is not shown, as it was measured in one patient (who had myocardial contusion) at presentation, and in none at follow-up

Data are shown as $n(\%)$ or as median $\left(\mathrm{P}_{25}-\mathrm{P}_{75}\right)$

$B p m$ beats per minute, $C I$ confidence interval, $C K-M B$ creatine kinase, muscle and brain isoenzyme, $C T$ computed tomography, ECG electrocardiography, $H s-T n T$ high sensitive troponin T, MAP mean arterial pressure, $N D$ not determined, TTE transthoracic echocardiography

\section{Literature review}

The search strategy resulted in 3443 records, of which 1665 remained after removing duplicates (Fig. 3). After applying inclusion criteria to title and abstract, 117 records remained.
Of these, 91 had to be excluded based upon the exclusion criteria. Review of reference lists of the 26 included manuscript yielded 2 studies that were missed in the selection process. Details on the 28 included manuscripts are shown in Supplemental Table S1 [2, 3, 8, 14, 21-23, 35-37, 41-58]. 
Table 3 Diagnostic properties of all diagnostic tests performed

\begin{tabular}{|c|c|c|c|c|}
\hline Test & $n$ & Prevalence $(95 \% \mathrm{CI})$ & Sensitivity (95\% CI) & Specificity $(95 \% \mathrm{CI})$ \\
\hline Chest X-ray & 114 & $37 \%(28-46 \%)$ & $0 \%(0-0 \%)$ & $100 \%(95-100 \%)$ \\
\hline Chest CT scan & 83 & $40 \%(29-51 \%)$ & $3 \%(0-16 \%)$ & $90 \%(78-97 \%)$ \\
\hline ECG at presentation & 96 & $36 \%(27-47 \%)$ & $14 \%(5-30 \%)$ & $92 \%(82-97 \%)$ \\
\hline ECG at follow-up ${ }^{a}$ & 37 & $46 \%(29-63 \%)$ & $6 \%(0-29 \%)$ & $90 \%(68-99 \%)$ \\
\hline TTE at presentation & 35 & $29 \%(14-46 \%)$ & $10 \%(0-45 \%)$ & $100 \%(86-100 \%)$ \\
\hline \multicolumn{5}{|l|}{ Cardiac biomarkers } \\
\hline TnT at presentation & 51 & $43 \%(29-58 \%)$ & $59 \%(36-79 \%)$ & $100 \%(88-100 \%)$ \\
\hline TnT at follow-up ${ }^{\mathrm{a}}$ & 48 & $29 \%(29-59 \%)$ & $86 \%(64-97 \%)$ & $93 \%(76-99 \%)$ \\
\hline Hs-TnT at presentation & 61 & $36 \%(24-49 \%)$ & $77 \%(55-92 \%)$ & $85 \%(69-94 \%)$ \\
\hline Hs-TnT at follow-up ${ }^{a}$ & 52 & $40 \%(27-55 \%)$ & $90 \%(70-99 \%)$ & $81 \%(63-93 \%)$ \\
\hline CK-MB at presentation & 108 & $41 \%(31-51 \%)$ & $75 \%(60-87 \%)$ & $63 \%(50-74 \%)$ \\
\hline CK-MB at follow-up ${ }^{\mathrm{a}}$ & 95 & $42 \%(32-53 \%)$ & $93 \%(80-98 \%)$ & $44 \%(30-57 \%)$ \\
\hline
\end{tabular}

Data for sensitivity and specificity are shown as \% (95\% CI)

Troponin I is not shown, as it was measured in one patient (who had myocardial contusion) at presentation, and in none at follow-up

$C I$ confidence interval, $C K-M B$ creatine kinase, muscle and brain isoenzyme, $C T$ computed tomography, $E C G$ electrocardiography, $H s-T n T$ high-sensitive troponin T, $\operatorname{Tn} T$ troponin T, TTE transthoracic echocardiography

${ }^{a}$ Median time to follow-up was 4 (2-10) days in patients with a myocardial contusion and 2 (2-3) days in patients without myocardial contusion for telemetric observation, and $4(3-7) \mathrm{h}$ in patients with a myocardial contusion and 4 (3-6) h in patients without myocardial contusion for laboratory tests
Twenty-four manuscripts were prospective studies. The total sample size of all studies was 7242 patients, of whom 1,048 $(14.5 \%)$ were labeled as having a myocardial contusion. The diagnostic criteria for myocardial contusion varied across studies, but mostly elevated cardiac biomarkers or abnormalities seen on electrocardiography or echocardiography, or a combination of both.

The risk of bias was judged as low for most studies in the domains of patient selection $(n=20)$, conduct or interpretation of the index test $(n=10)$, the reference standard ( $n=10)$, and patient flow and timing ( $n=15$; Fig. 4). Applicability concerns were judged as low risk of bias for most studies in the domains of patient selection $(n=22)$, index test $(n=14)$, and reference standard $(n=18)$.

Sensitivity and specificity of all diagnostic tests used per study are shown in Supplemental Figure S2, the pooled values are shown in Table 5. The enrolled studies did not allow pooling of data for hs-TnT. The heterogeneity for all diagnostic tests is large, as expressed by a significant Chi-square test and $I^{2}$ value $>50 \%$. This warrants careful interpretation of the pooled sensitivity and specificity. The pooled sensitivity of electrocardiography, troponin I, and CK-MB for identifying myocardial contusion varied between 62 and $71 \%$. Values were $45 \%$ for echocardiography and even $38 \%$ for troponin $\mathrm{T}$. The pooled specificity was generally better and ranged from $63 \%$ for CK-MB to $85 \%$ for troponin $\mathrm{T}$ and $88 \%$ for echocardiography. The area under the summary receiver operating curve ranged from 0.71 for $\mathrm{CK}-\mathrm{MB}$ to 0.91 for echocardiography.

\section{Discussion}

If a patient is presented to the hospital after having sustained blunt thoracic trauma, a myocardial contusion should be considered. Results of the current study show that the highest sensitivity and specificity are achieved when electrocardiography is combined with measuring cardiac biomarkers. This combination is best used for ruling in the disorder. Echocardiography is valuable for visual inspection of the heart. Chest X-ray and chest CT scan are valuable for identifying thoracic injuries and intrathoracic bleeding, but are not useful for identifying myocardial contusion.

The gold standard for identifying myocardial contusion is pathologic evaluation of the cardiac tissue post-mortem. Necrosis of cardiac myocytes is the only confirmative proof.

Since microscopic evaluation is not possible in a clinical setting, diagnostic tools such as electrocardiography, echocardiography, and measurement of cardiac biomarkers are needed.

The current meta-analysis supports the diagnostic algorithms that were recently published [59-61]. Based on our data, we suggest a diagnostic workup as depicted in Fig. 5. In line with the Advanced Trauma Life Support guidelines, a chest X-ray or CT scan is indicated for patients presenting to the hospital after blunt thoracic trauma [62]. These do not provide any information on cardiac involvement per se; however, these tests are required to rule out associated thoracic injuries which could serve as an alert to the possibility of a 


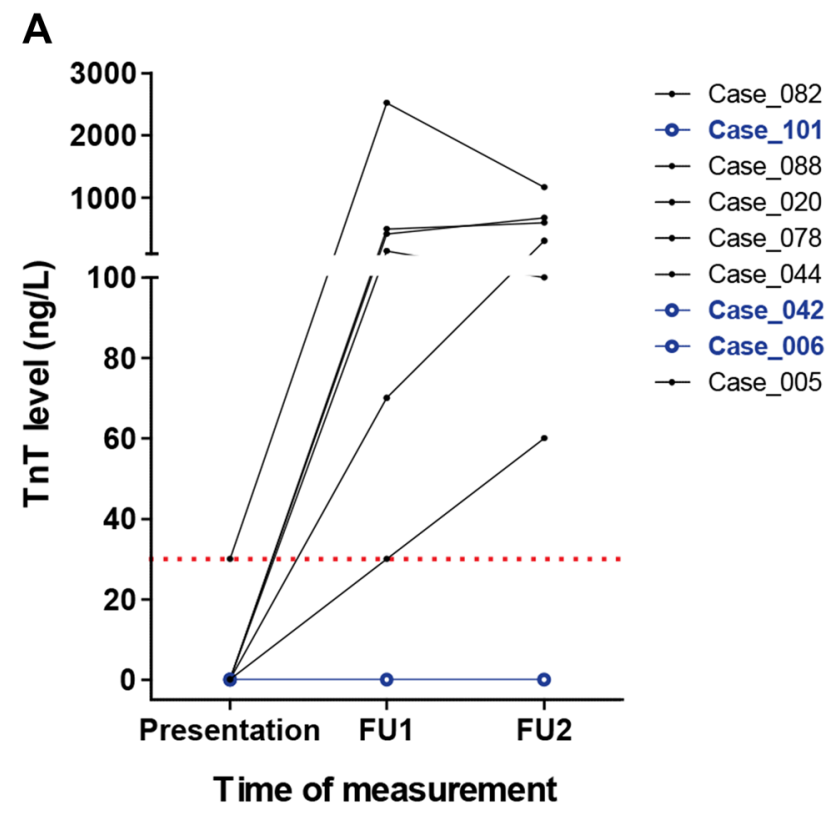

C

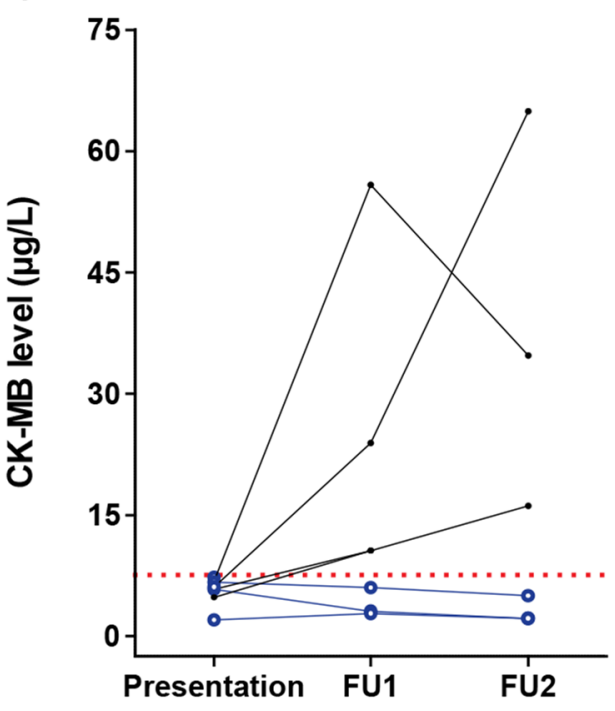

Time of measurement

Fig. 2 Change in cardiac biomarkers over time in patients with myocardial contusion who had their first measurement below the threshold value. Results are shown for a TnT, b hs-TnT, and CK-MB in c males and $\mathbf{d}$ females. Blue lines indicate patients with measurements

cardiac injury (e.g., pulmonary contusion or fractures of the rib or sternum) [63].

Upon presentation to the hospital, electrocardiography and measurement of cardiac biomarkers should routinely be done in patients who sustained blunt thoracic trauma. An electrocardiogram doubtful of myocardial contusion may reveal cardiac arrhythmias indicative for intraventricular conduction disorders, persistent atrial fibrillation, premature ventricular complexes, sinus tachycardia, a new
B

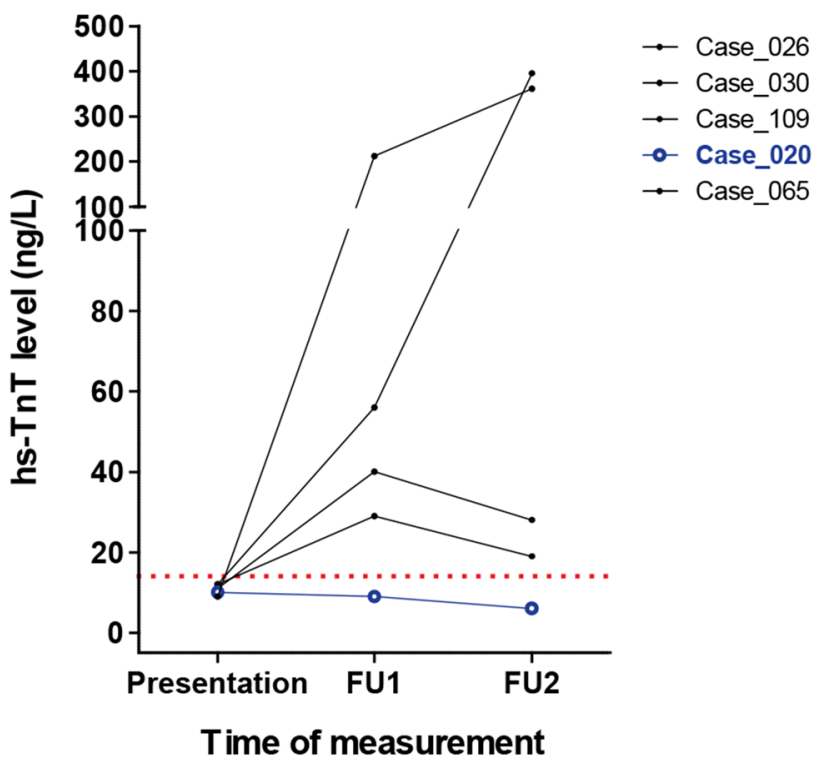

D

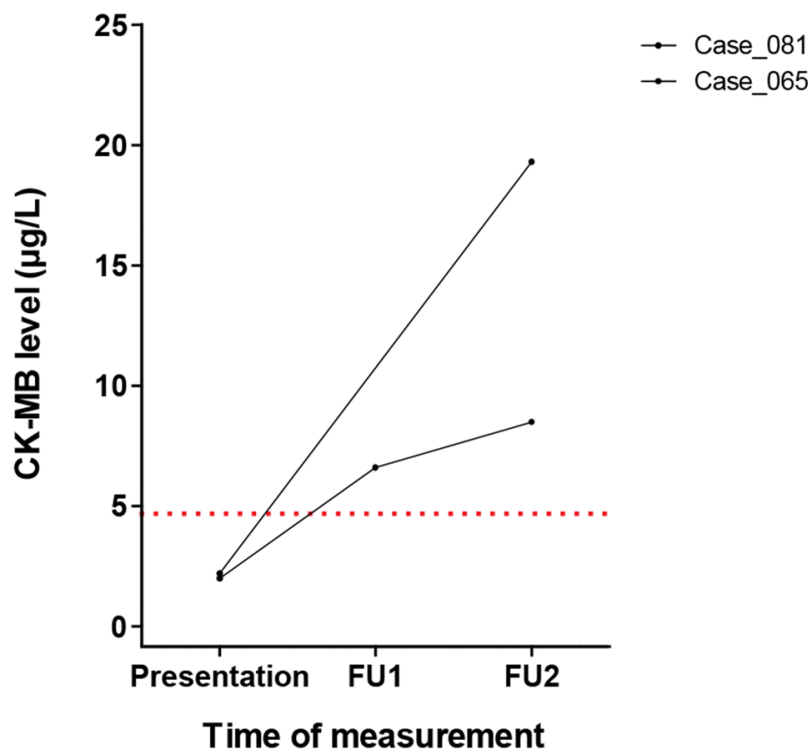

that remain below the threshold during follow-up. Red dotted lines show the threshold above which the cardiac biomarker is considered elevated. For CK-MB, males and females have a different threshold

bundle branch block, or ST depressions or elevations [9, 64-68]. Despite the fact that electrocardiography has low sensitivity and specificity when used alone [45], patients with an abnormal electrocardiogram develop more significant complications that require treatment [24]. The difficulty is to determine if the abnormality on an electrocardiogram is a primary event (e.g., an acute coronary syndrome that preceded trauma), a direct result of a cardiac 
Table 4 Adverse events and mortality of patients with versus without myocardial contusion

\begin{tabular}{lclll}
\hline Parameter & Overall $(n=117)$ & $\begin{array}{l}\text { Myocardial contu- } \\
\text { sion }(n=44)\end{array}$ & $\begin{array}{l}\text { No myocardial contu- } \\
\text { sion }(n=73)\end{array}$ & $p$ value \\
\hline Adverse events & $18(15 \%)$ & $15(34 \%)$ & $3(4 \%)^{\mathrm{a}}$ & $<0.001$ \\
Arrhythmias & $14(12 \%)$ & $13(30 \%)$ & $1(1 \%)^{\mathrm{a}}$ & $<0.001$ \\
$\quad$ Atrial fibrillation & $7(6 \%)$ & $7(16 \%)$ & $0(0 \%)$ & $\mathrm{ND}$ \\
PVC & $2(2 \%)$ & $2(5 \%)$ & $0(0 \%)$ & $\mathrm{ND}$ \\
$\quad$ Atrial flutter & $1(1 \%)$ & $1(2 \%)$ & $0(0 \%)$ & $\mathrm{ND}$ \\
Hypotension & $8(7 \%)$ & $6(14 \%)$ & $2(3 \%)$ & 0.051 \\
Cardiogenic shock & $1(1 \%)$ & $1(2 \%)$ & $0(0 \%)$ & 0.376 \\
Mortality & $7(6 \%)$ & $4(9 \%)$ & $3(4 \%)$ & 0.423 \\
\hline
\end{tabular}

Data are shown as $n(\%)$

$N D$ not determined, $P V C$ premature ventricular complexes

${ }^{a}$ This is excluding one patient for whom an electrocardiography before trauma already showed atrial fibrillation

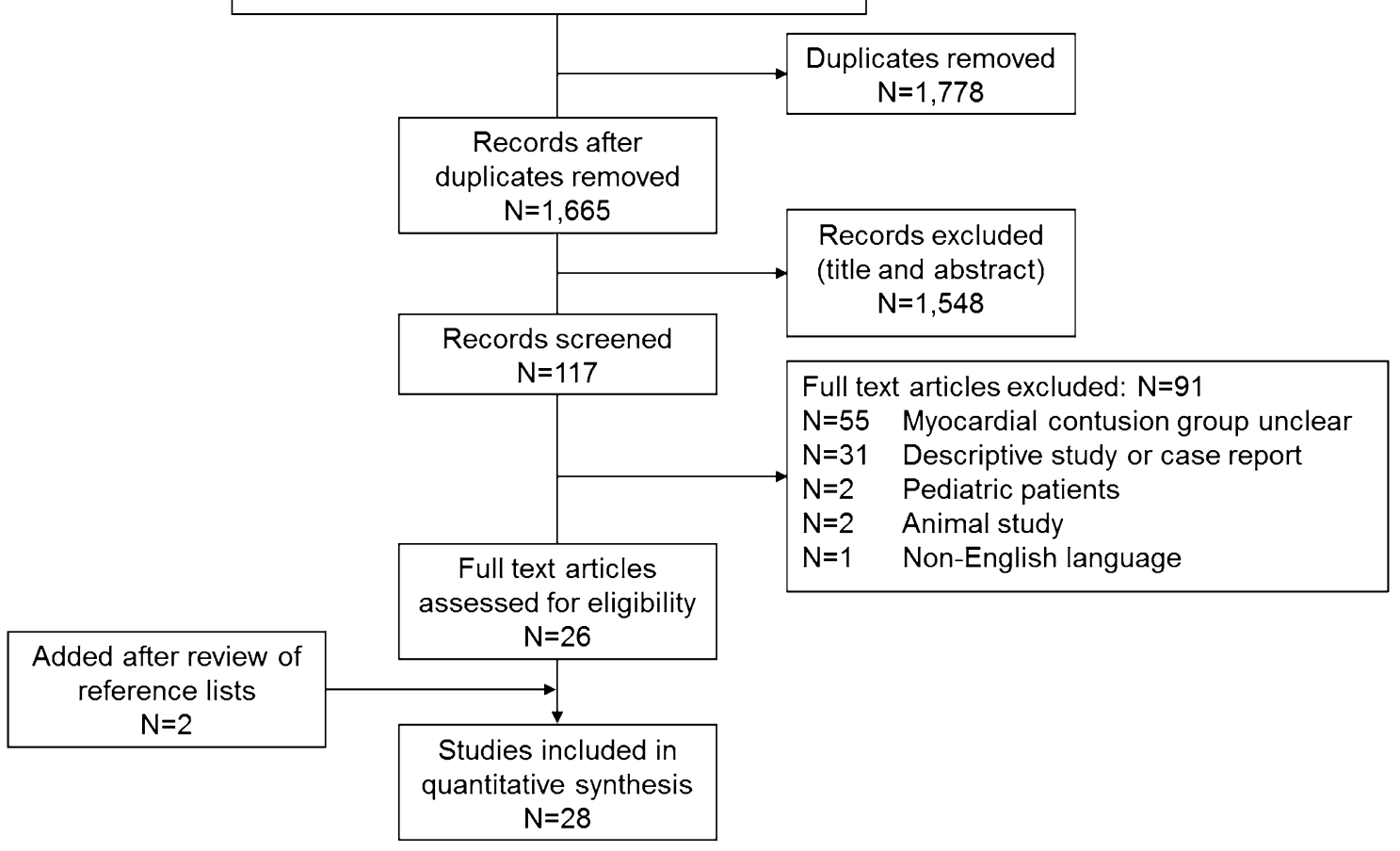

Fig. 3 Flowchart of literature search

injury, or a problem caused by the physiological stress of severe chest trauma.

Electrocardiography has consistently proven to be the best single overall predictor of blunt cardiac trauma [69]. However, electrocardiography alone is insufficient to completely exclude the diagnosis, and in a few rare cases has even missed significant blunt chest injuries [23, 47]. On the other hand, in our series, two control patients showed cardiac arrhythmias. Therefore, cardiac biomarkers (troponins $\mathrm{T}$ and I and CK-MB) should also be measured. Although the usefulness of cardiac biomarkers is unclear [36, 47], elevated troponin levels have been associated with increased 


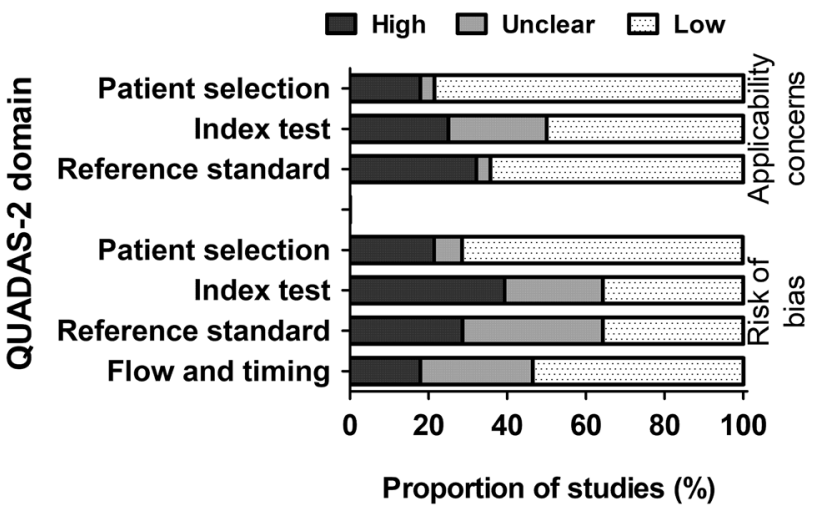

Fig. 4 Risk of bias and applicability concerns graph. Authors' judgements about each domain presented as percentages across included studies

mortality in patients with blunt thoracic trauma [42]. Although sensitivity and specificity of cardiac biomarkers vary largely across studies on myocardial contusion $[2,3,8$, 14, 21-23, 35-37, 41-58], our results show that sensitivity and specificity of the cardiac biomarkers is higher than that of echocardiography. Since other cardiac conditions may also result in cardiac biomarker elevation, cardiac biomarkers should be combined with either electrocardiography or echocardiography. Elevation of cardiac biomarkers can also be the result of hypovolemic shock, which is commonly seen in patients with significant chest trauma.

Electrocardiogram abnormalities or rising troponin values should prompt further evaluation using transthoracic echocardiography (TTE). This may reveal left or right ventricular systolic dysfunction, pericardial effusion with suspected tamponade, ventricular septal defect, or possible traumainduced valvular abnormalities [70].

Results from the electrocardiography (and echocardiography) and cardiac biomarkers support the subsequent diagnostic necessities and monitoring. Patients with abnormalities on the electrocardiography (or echocardiography) that are not explained by (non-)STEMI or by cardiac diseases that were already present pre-trauma, should be considered suspect for myocardial contusion. If cardiac biomarkers are also elevated, measurement of these markers should be repeated after $3 \mathrm{~h}$. In addition, telemonitoring is required for early knowledge of possible development of life-threatening arrhythmias or other complications. The patient data in this study confirm the relevance of this as 13 patients with myocardial contusion developed some form or arrhythmia over time. Cardiac monitoring should last at least $24-48 \mathrm{~h}$ because life-threatening ventricular arrhythmias, cardiac failure due to valve damage, cardiac tamponade due to a wall rupture, or acute coronary syndrome due to coronary artery dissection may develop within this period $[35,60$, $67,71,72]$.

If cardiac biomarkers are not elevated in patients with electrocardiography abnormalities, the biomarkers should be measured again after $3 \mathrm{~h}$, as they may become positive. If the cardiac biomarkers remain negative and no other clinical suspicion of myocardial contusion has emerged, the diagnosis can be rejected. Emerging clinical suspicion or elevated markers at follow-up, on the other hand, supports the presence of myocardial contusion. Telemonitoring is indicated in those patients.

If both cardiac biomarkers are not elevated and the electrocardiography shows no abnormalities, myocardial contusion is unlikely. It was shown previously that patients with a normal electrocardiogram in conjunction with normal levels of troponin can be safely discharged home [60, 67, 68]. However, our patient data show that clinical observation without telemonitoring may be needed for patients who have other traumatic thoracic diagnoses such as rib fractures.

The current study has several limitations. The most obvious limitations are the retrospective nature of the cohort study and the lack of a gold standard in both the cohort study and all studies in the literature review. Personal opinion of the treatment team may have led to false positive of false negative results for myocardial contusion. These differences in diagnostic criteria used, variation in biomarker cut off values, as well as differences in study population may have contributed to the heterogeneity across studies in the metaanalysis. This may have resulted in differences in sensitivity

Table 5 Pooled sensitivity and specificity of all diagnostic tests for identifying myocardial contusion for all studies identified in the systematic literature review

\begin{tabular}{|c|c|c|c|c|c|c|c|}
\hline \multirow[t]{2}{*}{ Test } & \multicolumn{3}{|l|}{ Sensitivity } & \multicolumn{3}{|l|}{ Specificity } & \multirow[t]{2}{*}{ AUC } \\
\hline & $\mathrm{Chi}^{2}(p)$ & $I^{2}(\%)$ & Pooled \% (95\% CI) & $\mathrm{Chi}^{2}(p)$ & $I^{2}(\%)$ & Pooled \% (95\% CI) & \\
\hline Electrocardiography & $165(<0.001)$ & 93 & $71 \%(66-75 \%)$ & $262(<0.001)$ & 96 & $75 \%(72-77 \%)$ & $0.86(0.04)$ \\
\hline Echocardiography & $43(<0.001)$ & 84 & $45 \%(37-53 \%)$ & $23(<0.001)$ & 69 & $88 \%(83-92 \%)$ & $0.91(0.08)$ \\
\hline \multicolumn{8}{|l|}{ Cardiac biomarkers } \\
\hline Troponin $\mathrm{T}$ & $26(0.001)$ & 88 & $38 \%(27-50 \%)$ & $61(<0.001)$ & 95 & $85 \%(83-87 \%)$ & $0.88(0.17)$ \\
\hline Troponin I & $33(<0.001)$ & 79 & $62 \%(53-69 \%)$ & $127(<0.001)$ & 95 & $76 \%(73-80 \%)$ & $0.80(0.07)$ \\
\hline CK-MB & $61(<0.001)$ & 86 & $66 \%(60-72 \%)$ & $291(<0.001)$ & 97 & $63 \%(59-67 \%)$ & $0.71(0.06)$ \\
\hline
\end{tabular}




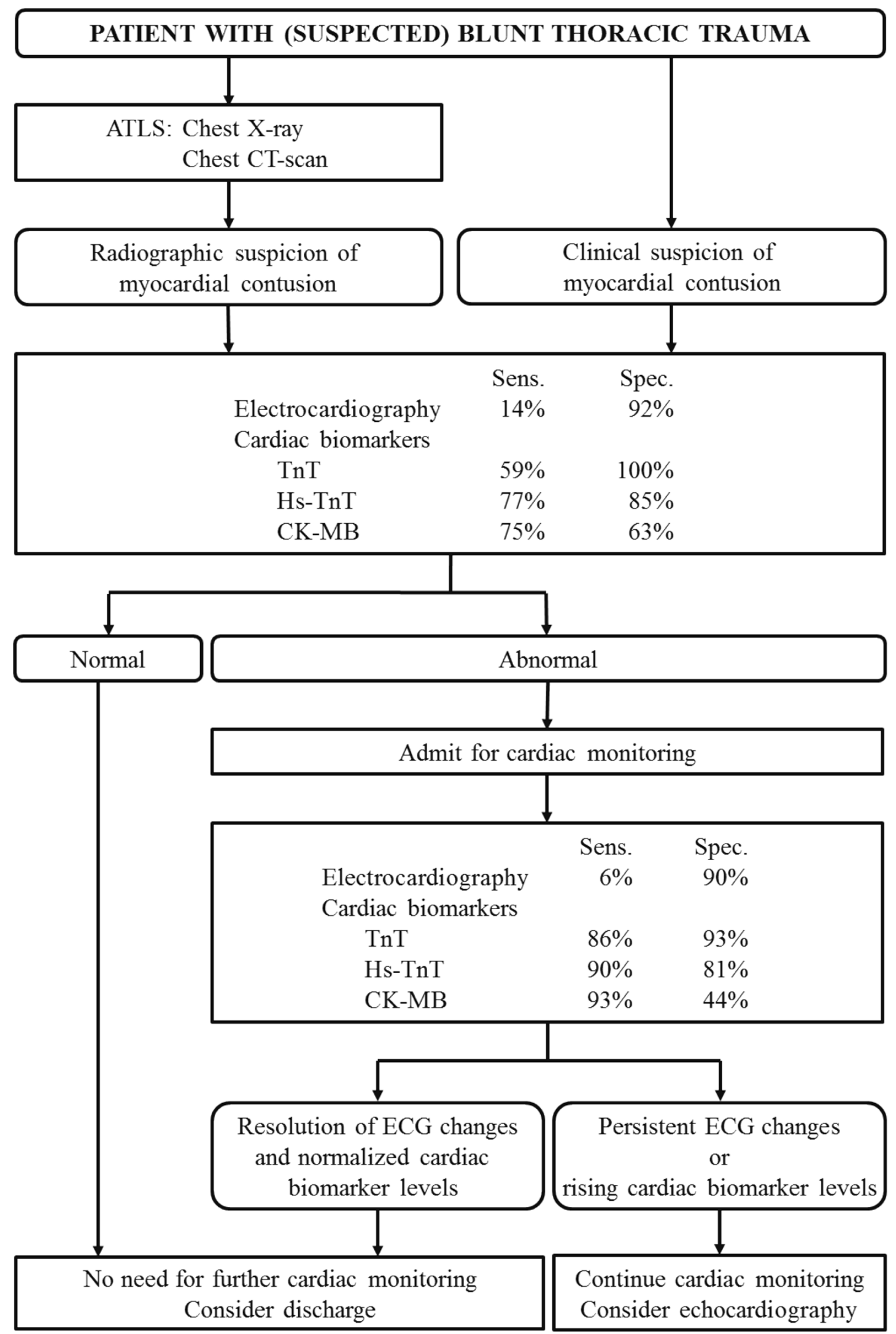

Fig. 5 Diagnostic algorithm for patients with blunt thoracic injuries with suspected myocardial contusion 
and specificity of the different diagnostic tests across the published as well as our cohort study. This heterogeneity also warrants careful interpretation of the pooled sensitivity and specificity.

\section{Conclusions}

Data from the current study support that initial diagnostic workup in patients who presented to a hospital after blunt thoracic trauma should consist of electrocardiography and measurement of cardiac biomarkers. If the electrocardiography shows abnormalities indicative of myocardial contusion and/or cardiac biomarkers are elevated at presentation or become elevated within the subsequent $3 \mathrm{~h}$, echocardiography and telemonitoring are indicated. If electrocardiography is normal and cardiac biomarkers remain negative, clinical observation may suffice. Further prospective studies are needed to refine the proposed diagnostic scheme.

Author contributions EMMVL, MHJV, DJTVS, and EAD designed the study; EMMVL and DJTVS collected data; DJTVS and EAD conducted the literature selection; EMMVL analyzed the data, DJTVS and EMMVL drafted the manuscript and all authors contributed substantially to its revision; EMMVL, MHJV, and EAD approved the final version. Due to his decease, DJTVS was unable to approve the final version.

Funding There was no financial support for this study.

\section{Compliance with ethical standards}

Conflict of interest EMM Van Lieshout, MHJ Verhofstad, DJT Van Silfhout, and EA Dubois declare that they have no conflict of interest.

Ethics approval and consent to participate The study was exempted by the local Medical Research Ethics Committee (Ref. nr. MEC-2017355). Consent was waived.

Open Access This article is licensed under a Creative Commons Attribution 4.0 International License, which permits use, sharing, adaptation, distribution and reproduction in any medium or format, as long as you give appropriate credit to the original author(s) and the source, provide a link to the Creative Commons licence, and indicate if changes were made. The images or other third party material in this article are included in the article's Creative Commons licence, unless indicated otherwise in a credit line to the material. If material is not included in the article's Creative Commons licence and your intended use is not permitted by statutory regulation or exceeds the permitted use, you will need to obtain permission directly from the copyright holder. To view a copy of this licence, visit http://creativecommons.org/licenses/by/4.0/.

\section{References}

1. Beresky R, Klingler R, Peake J. Myocardial contusion: when does it have clinical significance? J Trauma. 1988;28(1):64-8.
2. Adams JE 3rd, Davila-Roman VG, Bessey PQ, Blake DP, Ladenson JH, Jaffe AS. Improved detection of cardiac contusion with cardiac troponin I. Am Heart J. 1996;131(2):308-12.

3. Baxter BT, Moore EE, Moore FA, McCroskey BL, Ammons LA. A plea for sensible management of myocardial contusion. Am J Surg. 1989;158(6):557-61 (discussion 61-2).

4. Dubrow TJ, Mihalka J, Eisenhauer DM, de Virgilio C, Finch M, Mena IG, et al. Myocardial contusion in the stable patient: what level of care is appropriate? Surgery. 1989;106(2):267-73 (discussion 73-4).

5. Foil MB, Mackersie RC, Furst SR, Davis JW, Swanson MS, Hoyt $\mathrm{DB}$, et al. The asymptomatic patient with suspected myocardial contusion. Am J Surg. 1990;160(6):638-42 (discussion 42-3).

6. Gunnar WP, Martin M, Smith RF, Manglano R, Resnick DJ, Lopez V, et al. The utility of cardiac evaluation in the hemodynamically stable patient with suspected myocardial contusion. Am Surg. 1991;57(6):373-7.

7. McCarthy MC, Pavlina PM, Evans DK, Broadie TA, Park HM, Schauwecker DS. The value of SPECT-thallium scanning in screening for myocardial contusion. Cardiovasc Interv Radiol. 1991;14(4):238-40.

8. Wisner DH, Reed WH, Riddick RS. Suspected myocardial contusion. Triage and indications for monitoring. Ann Surg. 1990;212(1):82-6.

9. Nagy KK, Krosner SM, Roberts RR, Joseph KT, Smith RF, Barrett J. Determining which patients require evaluation for blunt cardiac injury following blunt chest trauma. World J Surg. 2001;25(1):108-11.

10. Leite L, Goncalves L, Nuno VD. Cardiac injuries caused by trauma: review and case reports. J Forensic Leg Med. 2017;52:30-4.

11. El-Chami MF, Nicholson W, Helmy T. Blunt cardiac trauma. J Emerg Med. 2008;35(2):127-33.

12. Frazee RC, Mucha P Jr, Farnell MB, Miller FA Jr. Objective evaluation of blunt cardiac trauma. J Trauma. 1986;26(6):510-20.

13. Kaye P, O'Sullivan I. Myocardial contusion: emergency investigation and diagnosis. Emerg Med J. 2002;19(1):8-10.

14. Sade R, Kantarci M, Ogul H, Bayraktutan U, Uzkeser M, Aslan $\mathrm{S}$, et al. The feasibility of dual-energy computed tomography in cardiac contusion imaging for mildest blunt cardiac injury. J Comput Assist Tomogr. 2016;41(3):354-9.

15. Baum V. Anesthetic complications during emergency noncardiac surgery in patients with documented cardiac contusions. J Cardiothorac Vasc Anesth. 1991;5(1):57-60.

16. King RM, Mucha P Jr, Seward JB, Gersh BJ, Farnell MB. Cardiac contusion: a new diagnostic approach utilizing two-dimensional echocardiography. J Trauma. 1983;23(7):610-4.

17. Mair J, Dienstl F, Puschendorf B. Cardiac troponin $T$ in the diagnosis of myocardial injury. Crit Rev Clin Lab Sci. 1992;29(1):31-57.

18. Okubo N, Hombrouck C, Fornes P, Cosson C, Samii K, Mazoit $\mathrm{JX}$, et al. Cardiac troponin I and myocardial contusion in the rabbit. Anesthesiology. 2000;93(3):811-7.

19. Olsovsky MR, Wechsler AS, Topaz O. Cardiac trauma. Diagnosis, management, and current therapy. Angiology. 1997;48(5):423-32.

20. Robert E, de La Coussaye JE, Aya AG, Bertinchant JP, Polge A, Fabbro-Peray P, et al. Mechanisms of ventricular arrhythmias induced by myocardial contusion: a high-resolution mapping study in left ventricular rabbit heart. Anesthesiology. 2000;92(4):1132-43.

21. Burrell AJ, Kaye DM, Fitzgerald MC, Cooper DJ, Hare JL, Costello BT, et al. Cardiac magnetic resonance imaging in suspected blunt cardiac injury: a prospective, pilot, cohort study. Injury. 2017;48(5):1013-9.

22. Bertinchant JP, Polge A, Mohty D, Nguyen-Ngoc-Lam R, Estorc J, Cohendy R, et al. Evaluation of incidence, clinical 
significance, and prognostic value of circulating cardiac troponin I and T elevation in hemodynamically stable patients with suspected myocardial contusion after blunt chest trauma. J Trauma. 2000;48(5):924-31.

23. Velmahos GC, Karaiskakis M, Salim A, Toutouzas KG, Murray J, Asensio J, et al. Normal electrocardiography and serum troponin I levels preclude the presence of clinically significant blunt cardiac injury. J Trauma. 2003;54(1):45-50 (discussion-1).

24. Maenza RL, Seaberg D, D'Amico F. A meta-analysis of blunt cardiac trauma: ending myocardial confusion. Am J Emerg Med. 1996;14(3):237-41.

25. Orliaguet G, Ferjani M, Riou B. The heart in blunt trauma. Anesthesiology. 2001;95(2):544-8.

26. Battle CE, Hutchings H, James K, Evans PA. The risk factors for the development of complications during the recovery phase following blunt chest wall trauma: a retrospective study. Injury. 2013;44(9):1171-6.

27. Unsworth A, Curtis K, Asha SE. Treatments for blunt chest trauma and their impact on patient outcomes and health service delivery. Scand J Trauma Resusc Emerg Med. 2015;23:17.

28. Adams JE, 3rd, Bodor GS, Davila-Roman VG, Delmez JA, Apple FS, Ladenson JH, et al. Cardiac troponin I. A marker with high specificity for cardiac injury. Circulation. 1993;88(1):101-6.

29. Fabian TC, Cicala RS, Croce MA, Westbrook LL, Coleman PA, Minard G, et al. A prospective evaluation of myocardial contusion: correlation of significant arrhythmias and cardiac output with CPK-MB measurements. J Trauma. 1991;31(5):653-9 (discussion 9-60).

30. Greenberg MD, Rosen CL. Evaluation of the patient with blunt chest trauma: an evidence based approach. Emerg Med Clin N Am. 1999;17(1):41-62, viii.

31. Healey MA, Brown R, Fleiszer D. Blunt cardiac injury: is this diagnosis necessary? J Trauma. 1990;30(2):137-46.

32. Miller FB, Shumate CR, Richardson JD. Myocardial contusion. When can the diagnosis be eliminated? Arch Surg. 1989;124(7):805-7 (discussion 7-8).

33. Bertinchant JP, Robert E, Polge A, de la Coussaye JE, Pignodel C, Aya G, et al. Release kinetics of cardiac troponin I and cardiac troponin $\mathrm{T}$ in effluents from isolated perfused rabbit hearts after graded experimental myocardial contusion. J Trauma. 1999;47(3):474-80.

34. Collins TF, Black TN, Brown LH, Bulhack P. Study of the teratogenic potential of FD \& C Yellow No. 5 when given by gavage to rats. Food Chem Toxicol. 1990;28(12):821-7.

35. Rajan GP, Zellweger R. Cardiac troponin I as a predictor of arrhythmia and ventricular dysfunction in trauma patients with myocardial contusion. J Trauma. 2004;57(4):801-8 (discussion 8).

36. Biffl WL, Moore FA, Moore EE, Sauaia A, Read RA, Burch JM. Cardiac enzymes are irrelevant in the patient with suspected myocardial contusion. Am J Surg. 1994;168(6):523-7 (discussion 7-8).

37. Fabian TC, Mangiante EC, Patterson CR, Payne LW, Isaacson ML. Myocardial contusion in blunt trauma: clinical characteristics, means of diagnosis, and implications for patient management. J Trauma. 1988;28(1):50-7.

38. Helm M, Hauke J, Weiss A, Lampl L. Cardiac troponin T as a biochemical marker of myocardial injury early after trauma. Diagnostic value of a qualitative bedside test. Chirurg. 1999;70(11):1347-52.

39. St Louis P, Gandhi S. Cardiac contusion and creatine kinase-MB: a pertinent case history and brief review of the utility of CK-MB. Clin Biochem. 1994;27(2):105-11.
40. Zamora J, Abraira V, Muriel A, Khan K, Coomarasamy A. MetaDiSc: a software for meta-analysis of test accuracy data. BMC Med Res Methodol. 2006;6:31.

41. Hammer MM, Raptis DA, Cummings KW, Mellnick VM, Bhalla $\mathrm{S}$, Schuerer DJ, et al. Imaging in blunt cardiac injury: computed tomographic findings in cardiac contusion and associated injuries. Injury. 2016;47(5):1025-30.

42. Mahmood I, El-Menyar A, Dabdoob W, Abdulrahman Y, Siddiqui $\mathrm{T}$, Atique $\mathrm{S}$, et al. Troponin $\mathrm{T}$ in patients with traumatic chest injuries with and without cardiac involvement: insights from an observational study. N Am J Med Sci. 2016;8(1):17-24.

43. Namrata G, Parshotam LG, Abhinav S, Tej KK, Navjot B, Neeru L, et al. Evaluation of myocardial contusion using biochemical markers in chest trauma patients. J Evol Med Dent Sci. 2015;4(69):12015-25.

44. Bahar AM, Nouri M, Alizadeh L, Namvar F, Asadi M. Estimated incidence of cardiac contusion using transthoracic echocardiography in patients suffering from severe blunt trauma to the chest. Acta Chir Belg. 2014;114(2):105-9.

45. Emet M, Akoz A, Aslan S, Saritas A, Cakir Z, Acemoglu H. Assessment of cardiac injury in patients with blunt chest trauma. Eur J Trauma Emerg Surg. 2010;36(5):441-7.

46. Mori F, Zuppiroli A, Ognibene A, Favilli S, Galeota G, Peris A, et al. Cardiac contusion in blunt chest trauma: a combined study of transesophageal echocardiography and cardiac troponin I determination. Ital Heart J. 2001;2(3):222-7.

47. Salim A, Velmahos GC, Jindal A, Chan L, Vassiliu P, Belzberg $\mathrm{H}$, et al. Clinically significant blunt cardiac trauma: role of serum troponin levels combined with electrocardiographic findings. J Trauma. 2001;50(2):237-43.

48. Boeken U, Feindt P, Gramsch-Zabel H, Raunest J, Micek M, Schulte HD, et al. The incidence of myocardial contusion in 160 patients with blunt chest trauma diagnostic criteria and outcome. Eur J Trauma. 2000;26(3):111-5.

49. Garcia-Fernandez MA, Lopez-Perez JM, Perez-Castellano N, Quero LF, Virgos-Lamela A, Otero-Ferreiro A, et al. Role of transesophageal echocardiography in the assessment of patients with blunt chest trauma: correlation of echocardiographic findings with the electrocardiogram and creatine kinase monoclonal antibody measurements. Am Heart J. 1998;135(3):476-81.

50. Ognibene A, Mori F, Santoni R, Zuppiroli A, Peris A, Targioni $\mathrm{G}$, et al. Cardiac troponin I in myocardial contusion. Clin Chem. 1998;44(4):889-90.

51. Swaanenburg JC, Klaase JM, DeJongste MJ, Zimmerman $\mathrm{KW}$, ten Duis HJ. Troponin I, troponin T, CKMB-activity and CKMB-mass as markers for the detection of myocardial contusion in patients who experienced blunt trauma. Clin Chim Acta. 1998;272(2):171-81.

52. Ferjani M, Droc G, Dreux S, Arthaud M, Goarin JP, Riou B, et al. Circulating cardiac troponin $\mathrm{T}$ in myocardial contusion. Chest. 1997;111(2):427-33.

53. Batouk A. Sternal fracture-regional experience. Ann Saudi Med. 1996;16(3):285-90.

54. Karalis DG, Victor MF, Davis GA, McAllister MP, Covalesky VA, Ross JJ Jr, et al. The role of echocardiography in blunt chest trauma: a transthoracic and transesophageal echocardiographic study. J Trauma. 1994;36(1):53-8.

55. Helling TS, Duke P, Beggs CW, Crouse LJ. A prospective evaluation of 68 patients suffering blunt chest trauma for evidence of cardiac injury. J Trauma. 1989;29(7):961-5 (discussion 5-6).

56. Bodin L, Rouby JJ, Viars P. Myocardial contusion in patients with blunt chest trauma as evaluated by thallium 201 myocardial scintigraphy. Chest. 1988;94(1):72-6. 
57. Macdonald RC, O’Neill D, Hanning CD, Ledingham IM. Myocardial contusion in blunt chest trauma: a ten-year review. Intensive Care Med. 1981;7(6):265-8.

58. Bayer MJ, Burdick D. Diagnosis of myocardial contusion in blunt chest trauma. JACEP. 1977;6(6):238-42.

59. Stolmeijer RT, Lameijer H. Myocardial contusion following trauma. Hartcontusie na een trauma. Ned Tijdschr Geneeskd. 2017;161:D1766.

60. Huis In 't Veld MA, Craft CA, Hood RE. Blunt cardiac trauma review. Cardiol Clin. 2018;36(1):183-91.

61. Singh S, Angus LD. Blunt cardiac injury. StatPearls [Internet]. Treasure Island: StatPearls Publishing; 2018.

62. Committee on Trauma, American College of Surgeons. ATLS: Advanced Trauma Life Support Program for Doctors. 8th ed. Chicago: American College of Surgeons. ISBN 978-1-880696-31-6; 2008.

63. Restrepo CS, Gutierrez FR, Marmol-Velez JA, Ocazionez D, Martinez-Jimenez S. Imaging patients with cardiac trauma. Radiographics. 2012;32(3):633-49.

64. Hossack KF, Moreno CA, Vanway CW, Burdick DC. Frequency of cardiac contusion in nonpenetrating chest injury. Am J Cardiol. 1988;61(4):391-4.
65. Tenzer ML. The spectrum of myocardial contusion: a review. J Trauma. 1985;25(7):620-7.

66. Bansal MK, Maraj S, Chewaproug D, Amanullah A. Myocardial contusion injury: redefining the diagnostic algorithm. Emerg Med J. 2005;22(7):465-9.

67. Elie MC. Blunt cardiac injury. Mt Sinai J Med. 2006;73(2):542-52.

68. Yousef R, Carr JA. Blunt cardiac trauma: a review of the current knowledge and management. Ann Thorac Surg. 2014;98(3):1134-40.

69. Fulda GJ, Giberson F, Hailstone D, Law A, Stillabower M. An evaluation of serum troponin $\mathrm{T}$ and signal-averaged electrocardiography in predicting electrocardiographic abnormalities after blunt chest trauma. J Trauma. 1997;43(2):304-10 (discussion 10-2).

70. Bock JS, Benitez RM. Blunt cardiac injury. Cardiol Clin. 2012;30(4):545-55.

71. Sybrandy KC, Cramer MJ, Burgersdijk C. Diagnosing cardiac contusion: old wisdom and new insights. Heart. 2003;89(5):485-9.

72. Oosterloo M, Nieuwland W, Zijlstra F. Myocardial contusion after blunt thoracic trauma: possible indication for rhythm observation. Myocardcontusie na een stomp thoraxtrauma: mogelijk indicatie tot ritmeobservatie. Ned Tijdschr Geneeskd. 2007;151(2):108-14. 